\title{
Frequency and Profile of Severe Periodontitis in Kinshasa Dental Hospitals, DR Congo
}

\author{
Em K. Kalala ${ }^{*}$, Fidèle B. Nyimi ${ }^{2}$, Béatrice K. Ngamala ${ }^{3}$, Jean-Paul I. Sekele ${ }^{4}$, Alain K. Nyengele ${ }^{4}$, \\ Pierre M. Muyembi ${ }^{2}$, Jacques I. Bolenge ${ }^{1}$, Hubert M. Ntumba ${ }^{2}$ \\ ${ }^{1}$ Unit of Periodontology, Department of Dental Medicine, Faculty of Medicine, University of Kinshasa, Kinshasa, Democratic \\ Republic of Congo \\ ${ }^{2}$ Service of Stomatology and Maxillo-Facial Surgery, Department of Dental Medicine, Faculty of Medicine, University of Kinshasa, \\ Kinshasa, Democratic Republic of Congo \\ ${ }^{3}$ Béatrice Ngamala Kabongo: DDS, Private Practice, Kinshasa, Democratic Republic of Congo \\ ${ }^{4}$ Service of Prosthodontics and Orthodontics, Department of Dental Medicine, Faculty of Medicine, University of Kinshasa, \\ Kinshasa, Democratic Republic of Congo \\ Email: *kalalaem@gmail.com
}

How to cite this paper: Kalala, E.K., Nyimi, F.B., Ngamala, B.K., Sekele, J.-P.I., Nyengele, A.K., Muyembi, P.M., Bolenge, J.I. and Ntumba, H.M. (2018) Frequency and Profile of Severe Periodontitis in Kinshasa Dental Hospitals, DR Congo. Health, 10, 396-402.

https://doi.org/10.4236/health.2018.104032

Received: February 5, 2018

Accepted: April 15, 2018

Published: April 18, 2018

Copyright (c) 2018 by authors and Scientific Research Publishing Inc. This work is licensed under the Creative Commons Attribution International License (CC BY 4.0).

http://creativecommons.org/licenses/by/4.0/

\section{c) (i) Open Access}

\begin{abstract}
Purpose: Severe periodontitis (SP) is the sixth most prevalent disease worldwide. Prevalence and incidence are poorly reported in DR Congo. The aim of this study was to assess the prevalence of SP and to compare its profile with that of mild to moderate periodontitis (MMP). Materials and Methods: Four hundred and four patients from four hospitals of Kinshasa City Capital participated in this study. Probing pocket depth (PPD) at six sites per tooth, bleeding on probing (BoP) and plaque index (PIl) were the main clinical parameters assessed. Results: Out of 404 patients examined in this study, 92 (22.8\%) had severe periodontitis and $276(68.3 \%)$ had mild to moderate periodontitis. Among patients with SP, 48 (52\%) were female, 44 (48\%) were male and $63 \%$ of them had a PPD of $6 \mathrm{~mm}$. SP was significantly different from MMP according to patients age, $47.3 \pm 18.6$ versus $32.87 \pm 14.40$ years old, $\mathrm{p}<$ 0.001; plaque index, $1.153 \pm 0.39$ versus $0.90 \pm 0.39, \mathrm{p}<0.001$; BoP, 26.65 versus 17.04, $\mathrm{p}<0.001$. Conclusion: The Frequency of SP is relatively high in patients attending dental services in Kinshasa City and SP is significantly different from MMP.
\end{abstract}

\section{Keywords}

Bleeding on Probing, Mild/Moderate Periodontitis, Prevalence, Probing Pocket Depth, Severe Periodontitis

\section{Introduction}

Periodontitis is a prevalent destructive gum disease characterized by loss of 
supporting periodontal ligament and alveolar bone [1] [2].

Subgingival plaque bacteria initiate the inflammation, but the host response is determinant in the onset and progression of the disease. Risk factors including environmental, systemic and genetic factors may modify this process [3]. Periodontitis is associated with the diseases and conditions like cardiovascular diseases, diabetes mellitus, respiratory diseases, preterm labor and low birth infants [4] [5] [6] [7].

Periodontitis causes microulceration of the investing sulcular and pocket lining epithelium. The estimated surface area of this ulcerated epithelium approximates $40 \mathrm{~cm}^{2}$ in severe periodontitis. The prevalence of SP varies worldwide. In the USA it's $8.9 \%$ [8], 20\% in East Germany [9] and $11.9 \%$ as study reported result from Australia [10]. While mild to moderate periodontitis affects the majority of adults, severe periodontitis (SP) affects $5 \%$ to $20 \%$ of any population [11] [12].

In a systematic review and meta-regression analysis by Kassenbaum et al. [13], SP was found to affect 748 millions of people worldwide and is the sixth most prevalent condition. The loss of productivity due to SP amounted to US $\$ 54$ billion yearly worldwide [14].

To the best of our knowledge, the prevalence or incidence of SP is poorly reported in DR Congo and also no study has yet compared subjects with severe periodontitis and those with mild to moderate periodontitis. The objective of the present study was to determine the frequency of SP and to compare its profile with that of MMP.

\section{Materials and Methods}

This cross-sectional study took place in four hospitals selected randomly in the province of Kinshasa from October 2012 to April 2013. These centers were Ngaliema clinic, Boyambi clinic, Saint Joseph hospital and affiliated clinic of Kinshasa University.

The study was approved by the local ethic committee, school of public health of the University of Kinshasa, approval number ESP/015/2012. An informed consent was obtained from each participant and pertinent information concerning the study was explained to all of them.

The study assessed 404 subjects aged between 12 and 81 years who consulted the dental services of mentioned above hospitals. Their mean age was $35.26 \pm$ 16.94 with a median of 30 years, a sex ratio of 1.49:1 and the most represented age group between 20 and 29 years old (Table 1).

The data were collected by interview and a clinical exam. The subject comfortably seated on a dental chair was first interviewed and then a periodontal clinical examination was performed by the same trained and calibrated examiner (E.K.K). The parameters of interest were socio-demographic data and anamnestic informations on the interview. On clinical examination, the plaque index (PII), bleeding on probing (BoP), and probing pocket depth (PPD) were assessed. The PII was calculated as the sum of scores of all surfaces examined divided by the total number of surfaces examined. BoP was calculated as the sum 
Table 1. Age group of participants.

\begin{tabular}{ccc}
\hline Age group (years) & Number of patients & Percentage \\
\hline $\mathbf{1 2}-\mathbf{1 9}$ & 62 & 15.3 \\
$\mathbf{2 0}-\mathbf{2 9}$ & 138 & 34.2 \\
$\mathbf{3 0}-\mathbf{3 9}$ & 74 & 18.3 \\
$\mathbf{4 0}-\mathbf{4 9}$ & 43 & 10.6 \\
$\mathbf{5 0}-\mathbf{5 9}$ & 41 & 10.1 \\
$\mathbf{6 0}-\mathbf{6 9}$ & 24 & 5.9 \\
$\geq \mathbf{7 0}$ & 22 & 5.4 \\
Total & 404 & 100 \\
\hline
\end{tabular}

of the surfaces that bled after probing divided by the number of the surfaces examined. The bleeding was assessed 20 seconds after the passage of a periodontal probe into the sulcus.

The examination started on the disto-buccal surface of the maxillary right second molar, and continued anteriorly to the disto-buccal surface of the maxillary left second molar. Then, the disto-lingual surface of the maxillary right second molar was examined to the disto-lingual surface of the maxillary left second molar. The mandibular teeth were then examined in the same manner, starting on the disto-buccal surface of the mandibular right second molar.

All fully erupted permanent teeth were examined, excluding the third molars. Erupting teeth, supernumerary and partially impacted teeth were excluded. The measurements were assessed at six sites per tooth (mesiobuccal, midbuccal, distobuccal, mesiolingual, midlingual and distaolingual). The PPD was defined as the distance between the free gingival margin to the bottom of the pocket/sulcus. The periodontal probe (Hu-Friedy, PCP 11.5, CHICAGO, Illinois) was used for probing depth measurements and bleeding on probing.

In this study, we defined subject with periodontitis as the patient with a probing pocket depth of at least $3.5 \mathrm{~mm}$ on at least one tooth. The patient with SP was defined as the one with a PPD of at least $6 \mathrm{~mm}$ on at least one tooth.

The data collected were entered into the computer using Excel 2007 software. The SPSS software version 20.0 was used for descriptive statistics. The Student's T-test and Analyze of Variance (ANOVA) were used to compare the means. The significance level was set at $0.05 \%$.

\section{Results}

Out of 404 patients examined in the present study, 242 (59.9\%) female and 162 (40.1\%) male, 92 (22.8\%) had severe periodontitis (Table 2).

Among SP patients, forty-eight were female (52\%) and forty-four (48\%) were male. The mean age of SP patients was 47.3 (SD \pm 18.60$)$ years and a median of 46 years old.

The proportion of subjects with $\mathrm{PPD}=6 \mathrm{~mm}$ was $63 \%$ and those with a PPD $=$ $7 \mathrm{~mm}$ was $23.9 \%$ (Table 3 ). 
Table 2. Frequency of severe, moderate and mild periodontitis.

\begin{tabular}{ccc}
\hline Periodontitis & Number of patients & Percentage \\
\hline Mild & 176 & 43.6 \\
Moderate & 100 & 24.7 \\
Severe & 92 & 22.8 \\
Healthy & 38 & 9.4 \\
Total & 404 & 100 \\
\hline
\end{tabular}

Mild: 3.5 - $4.5 \mathrm{~mm}$, Moderate: 5 - $5.5 \mathrm{~mm}$, Severe: $\geq 6 \mathrm{~mm}$, Healthy: $\leq 3 \mathrm{~mm}$.

Table 3. Occurrence of PPD on at least one tooth in SP patients.

\begin{tabular}{ccc}
\hline PPD & Number of patients & Percentage \\
\hline $6 \mathrm{~mm}$ & 58 & 63.0 \\
$6,5 \mathrm{~mm}$ & 2 & 2.2 \\
$7 \mathrm{~mm}$ & 22 & 23.9 \\
$8 \mathrm{~mm}$ & 2 & 2.2 \\
$9 \mathrm{~mm}$ & 6 & 6.5 \\
$10 \mathrm{~mm}$ & 2 & 2.2 \\
Total & 92 & $100 \%$ \\
\hline
\end{tabular}

PPD: probing pocket depth, SP: severe periodontitis.

Comparing the SP patients and MMP patients, there was significant difference between SP and MMP according to age, $47.3 \pm 18.6$ versus $32.87 \pm 14.40$ years old, $\mathrm{p}<0.001$; plaque index, $1.153 \pm 0.385$ versus $0.90 \pm 0.385, \mathrm{p}<0.001 ; \mathrm{BoP}$, 26.65 versus $17.039, \mathrm{p}<0.001$ (Table 4 ).

\section{Discussion}

The objective of this study was to assess the prevalence of SP among patients attending hospitals in Kinshasa and to compare its profile with that of MMP.

The present study showed a high prevalence of SP. In Norwegian circumpolar communities, the SP prevalence of $9.1 \%$ was found [15]. But a study of large population in West Pomerania in the former East Germany found 20\% of SP [9] whereas NHANES 2009-2012 estimated that about $8.9 \%$ of the US adult population aged 30 years and older had SP [8]. A meta-analysis study by Kassenbaum et al. [13] has concluded that SP affected $5 \%$ to $20 \%$ of people worldwide, indeed, the majority of adult population had MMP. In this study, $22.8 \%$ of subjects have SP whereas $68.3 \%$ has MMP indicating that the proportion of SP is high but fewer than that of MMP. This is in agreement with others studies where the proportion of MMP was greater than that of SP and MMP was common and affected the majority of adults [11] [12]. Proportions of periodontitis can vary according to the methodologies and diagnostic criteria used [16] [17]. It should be noted that, the criteria used in this study defined MMP as the presence of a PPD of at least $3.5 \mathrm{~mm}$ on at least one tooth and SP as the presence of a PPD of $6 \mathrm{~mm}$ 
Table 4. Comparison between SP and MMP according to age, PlI and BoP.

\begin{tabular}{cccccc}
\hline \multirow{2}{*}{ Variable } & \multicolumn{2}{c}{ MMP } & \multicolumn{2}{c}{ SP } & \multirow{2}{*}{ p-Value } \\
\cline { 2 - 5 } & $\mathbf{N}$ & Mean & N & Mean & \\
\hline Age & 274 & $32.87 \pm 14.40$ & 92 & $47.30 \pm 18.60$ & $<0.001$ \\
PII & 274 & $0.90 \pm 0.39$ & 92 & $1.153 \pm 0.39$ & $<0.001$ \\
BoP & 274 & $17.04 \pm 14.11$ & 92 & $26.65 \pm 21$ & $<0.001$ \\
\hline
\end{tabular}

Values are presented as mean \pm standard deviation. MMP: mild to moderate periodontitis, SP: severe periodontitis, BoP: bleeding on probing, PlI: plaque index.

or over on at least one tooth. The majority of patients had PPD of $6 \mathrm{~mm}$.

The mean age of SP patients was higher than that of MMP patients with significant difference. SP seems to be more prevalent in older age and this was consistent with the literature showing that periodontitis prevalence and severity of disease are associated with increasing age [8] [11] [18]. Age is considered as an aggravating factor in the fact that the cumulative effect of the disease during the life of the individual is measured [3] [19].

The plaque index expresses the level of dental plaque. It can be used to qualify whether the individual has or not a poor oral hygiene. There is pronounced relationship between poor oral hygiene and increased accumulation of dental plaque, high prevalence and increased severity of periodontal disease [20]. Dental plaque can set a stage for inflammatory changes in periodontal tissues [21]. In the etiology of periodontal diseases, dental plaque as dental biofilm is considered as the primary factor that initiates the inflammation. According to the host response, this inflammation can lead to the tissues breakdown. Also other factors, such as environmental, genetics or systemic may play an important role. In a prospective study of 15 years duration, Axelsson et al. found no further deterioration of periodontal structure among the subjects who maintained proper oral hygiene and took routine professional dental care [22]. In this study, the PII of SP patients was significantly greater than that of MMP patients.

Bleeding on probing was demonstrated to be a sign of inflammation of gingival tissue or a proxy for gingival inflammation [23]. The presence of BoP may be considered as a predictor for the progression of periodontal disease [24], whereas its absence is a reliable predictor for the maintenance of periodontal health [25]. BoP is at present a clinical sign of periimplant disease. In this study, BoP of patients with SP was significantly higher than that of MMP patients. Inflammation by means of BoP is greater in patients with SP. The presence of deep pockets may influence the accumulation of dental plaque and the microorganisms within the biofilm may act in maintaining the inflammation.

This study has some limitations; it was carried out in patients attending hospitals and therefore is prone to selection bias. The prevalence found here is the prevalence of patients consulting the dental services of Kinshasa in DR Congo. Future studies involving randomly sample selected in population are needed.

Within the limitations of this study, it provides information on the frequency 
of SP which is high in patients attending dental services in Kinshasa. It also demonstrate that variables such PII and BoP and age are significantly different between SP patients and MMP patients.

\section{Acknowledgements}

We thank Dr. Peter Mbayabu for his great contribution in elaborating tables.

\section{Conflict of Interest}

The authors state explicitly that there are no conflicts of interest in this study.

\section{Funding}

No funding, apart from the authors themselves was available for this study.

\section{References}

[1] Eke, P.I., Dye, B.A., Wei, L., Thornton-Evans, G.O. and Genco, R.J. (2012) Prevalence of Periodontitis in Adults in the United States: 2009 and 2010. Journal of Dental Research, 91, 914-920. https://doi.org/10.1177/0022034512457373

[2] Pihlstrom, B.L., Michalowicz, B.S. and Johnson, N.W. (2005) Periodontal Diseases. Lancet, 366, 1809-1820. https://doi.org/10.1016/S0140-6736(05)67728-8

[3] Beck, J.D. and Arbes Jr., J. (2007) Epidemiology of Gingival and Periodontal Diseases. In: Newman, M.G., Takei, H.T., Klokkevold, P.R. and Carranza, F.A., Eds., Carranza's Clinical Periodontology, 10th Edition, Saunders Elsevier, St. Louis, 110-131.

[4] Offenbacher, S., Katz, V., Fertik, G., Collins, J., Boyd, D., Maynor, G., et al. (1996) Periodontal Disease as a Possible Risk Factor for Preterm Low Birth Weight. Journal of Periodontology, 67, 1103. https://doi.org/10.1902/jop.1996.67.10s.1103

[5] Offenbacher, S., Jarad, H.L., O’Reilly, P.G., Wells, S.R., Salvi, G.E., Lawrence, H.P., et al. (1998) Potential Pathogenic Mechanisms of Periodontitis-Associated Pregnancy Complications. Annals of Periodontology, 3, 233. https://doi.org/10.1902/annals.1998.3.1.233

[6] Scannapieco, F.A., Bush, R.B. and Paju, S. (2003) Association between Periodontal Disease and Risk for Atherosclerosis, Cardiovascular Disease, and Stroke: A Systematic Review. Annals of Periodontology, 8, 38. https://doi.org/10.1902/annals.2003.8.1.38

[7] Mealey, B.L. and Klokkevold, P.R. (2007) Periodontal Medicine: Impact of Periodontal Infection on Systemic Health. In: Newman, M.G., Takei, H.T., Klokkevold, P.R. and Carranza, F.A., Eds., Carranza's Clinical Periodontology, 10th Edition, Saunders Elsevier, St. Louis, 314-329.

[8] Eke, P.I., Dye, B.A., Wei, L., Slade, G.D., Thornoton-Evans, G.O., Borgnakke, W.S., et al. (2015) Update on Prevalence of Periodontitis in Adults in the United States: NHANES 2009-2012. Journal of Periodontology, 86, 611-622. https://doi.org/10.1902/jop.2015.140520

[9] Zhan, Y., Holtfreter, B., Meisel, P., Hoffmann, T., Micheelis, W., Dietrich, T., et al. (2014) Prediction of Periodontal Disease: Modeling and Validation in Different General German Populations. Journal of Clinical Periodontology, 41, 224-231. https://doi.org/10.1111/jcpe.12208

[10] Roberts-Thomson, K.F., Do, L.G., Bartold, P.M., Daniels, J., Grosse, A. and Meihu- 
bers, S. (2014) Prevalence, Extent and Severity of Severe Periodontal Destruction in an Urban Aboriginal and Torres Strait Islander Population. Australian Dental Journal, 59, 43-47. https://doi.org/10.1111/adj.12138

[11] Dye, B.A. (2012) Global Periodontal Disease Epidemiology. Periodontology, 58, 10-25. https://doi.org/10.1111/j.1600-0757.2011.00413.x

[12] Petersen, P.E. and Ogawa, H. (2012) The Global Burden of Periodontal Disease: Towards Integration with Chronic Disease Prevention and Control. Periodontology, 60, 15-39. https://doi.org/10.1111/j.1600-0757.2011.00425.x

[13] Kassenbaum, N.J., Bernabé, E., Dahiya, M., Bhandari, B., Murray, C.J.L. and Marcenes, W. (2014) Global Burden of Severe Periodontitis in 1990-2010: A Systematic Review and Meta-Regression. Journal of Dental Research, 93, 1045-1053. https://doi.org/10.1177/0022034514552491

[14] Tonetti, M.S., Jepsen, S., Jin, L. and Otomo-Corgel, J. (2017) Impact of the Global Burden of Periodontal Diseases on health, nutrition and Wellbeing of Mankind: A Call for Global Action. Journal of Clinical Periodontology, 44, 456-462. https://doi.org/10.1111/jcpe.12732

[15] Holde, G.E., Oscarson, N., Trovik, T.A., Tillberg, A. and Jönsson, B. (2017) Periodontitis Prevalence and Severity in Adults: A Cross-Sectional Study in Norwegian Circumpolar Communities. Journal of Periodontology, 88, 1021-1022. https://doi.org/10.1902/jop.2017.170164

[16] Preshaw, P.M. (2009) Definitions of Periodontal Disease in Research. Journal of Clinical Periodontology, 36, 1-2. https://doi.org/10.1111/j.1600-051X.2008.01320.x

[17] Amir, S., Eaton, K.A., Moles, D.R. and Needleman, I. (2009) A Systematic Review of Definitions of Periodontitis and Methods That Have Been Used to Identify This Disease. Journal of Clinical Periodontology, 36, 458-467. https://doi.org/10.1111/j.1600-051X.2009.01408.x

[18] Kazadi, E.K., Masin, S.S., Fidele, N.B., Sekele, I.B.J.P., Bolenge, J., Mantshumba, A., et al. (2017) Profile of Aggressive and Chronic Periodontitis in Kinshasa Dental Hospitals, DR Congo. Open Journal of Stomatology, 7, 439-447.

[19] Genco, R.J. (1996) Current View of Risk Factors for Periodontal Diseases. Journal of Periodontology, 67, 1041-1049.

[20] Albandar, J.M. (2000) Global Risk Factors and Risk Indicators for Periodontal Diseases. Periodontology, 29, 177-206. https://doi.org/10.1034/j.1600-0757.2002.290109.x

[21] De Oliveira, C., Watt, R.N. and Hamer, M. (2010) Toothbrushing, Inflammation, and Risk of Cardiovascular Disease: Results from Health Survey. BMJ, 340, c2451.

[22] Axelsson, P., Lindhe, J. and Nyström, B. (1991) On the Prevention of Caries and Periodontal Disease. Results of a 15-Year Longitudinal Study in Adults. Journal of Clinical Periodontology, 18, 182-189. https://doi.org/10.1111/j.1600-051X.1991.tb01131.x

[23] Bouchard, P., Carra, M.C., Boillot, A., Mora, F. and Rangé, H. (2017) Risk Factors in Periodontology: A Conceptual Framework. Journal of Clinical Periodontology, 44, 125-131. https://doi.org/10.1111/jcpe.12650

[24] Lang, N.P., Joss, A., Orsanic, T., Gusberti, F.A. and Siegrist, B.E. (1986) Bleeding on Probing. A Predictor for the Progression of Periodontal Disease? Journal of Clinical Periodontology, 13, 590-596. https://doi.org/10.1111/j.1600-051X.1986.tb00852.x

[25] Lang, N.P., Adler, R., Joss, A. and Nyman, S. (1990) Absence of Bleeding on Probing. An Indicator of Periodontal Stability. Journal of Clinical Periodontology, 17, 714-721. https://doi.org/10.1111/j.1600-051X.1990.tb01059.x 